\title{
Saltatory rolling circle amplification for sensitive visual detection of Staphylococcus aureus in milk
}

\author{
Qian Yang, ${ }^{1 *}$ Yunzhe Zhang, ${ }^{2 *}$ Sen $\mathrm{Li}^{2}{ }^{2}$ Xin Lu, ${ }^{1}$ Yaowu Yuan, ${ }^{2}$ and Wei Zhang ${ }^{1,2,3} \dagger$ \\ ${ }^{1}$ College of Science and Technology, Hebei Agricultural University, Cangzhou 061100, China \\ ${ }^{2}$ College of Food Science and Technology, Hebei Agricultural University, Baoding 071001, China \\ ${ }^{3}$ College of Life Sciences, Hebei Agricultural University, Baoding 071001, China
}

\section{ABSTRACT}

Monitoring Staphylococcus aureus with high sensitivity is very important for ensuring milk quality and food safety. In this study, we used a rapid nucleic acid isothermal amplification method, saltatory rolling circle amplification (SRCA), for the detection of Staph. aureus in milk. The results of the SRCA method can be assessed visually by the presence of white precipitate or by fluorescence measurement. Thirteen Staph. aureus strains and 31 non-Staph. aureus strains were used to evaluate the specificity of SRCA. The method exhibited excellent detection of Staph. aureus genomic DNA at a concentration of $7.8 \times 10^{1} \mathrm{fg} / \mu \mathrm{L}$ when assessed by visible precipitate, and at $7.8 \times 10^{0} \mathrm{fg} / \mu \mathrm{L}$ when detected by fluorescence after addition of the fluorochrome SYBR Green I. In artificially inoculated milk, the detection limits of SRCA were $5.6 \times 10^{2} \mathrm{cfu} /$ $\mathrm{mL}$ by precipitate and $5.6 \times 10^{1} \mathrm{cfu} / \mathrm{mL}$ by fluorescence, respectively. Compared with conventional PCR approaches, the SRCA assay achieved at least 100-fold higher sensitivity. Moreover, the sensitivity, specificity, and accuracy of the SRCA-based system were calculated to be $100.00,97.73$, and $97.78 \%$, respectively. These results indicate that SRCA has potential application as a sensitive and visual technique for the detection of Staph. aureus in milk.

Key words: saltatory rolling circle amplification (SRCA), Staphylococcus aureus, visualization, detection

\section{INTRODUCTION}

Bovine mastitis is an important disease in the dairy industry worldwide, resulting in economic losses and decreased quality and production of milk (Silva et al., 2013; Zhang et al., 2015). Multiple pathogens are

Received April 1, 2019.

Accepted July 7, 2019.

*These authors contributed equally to this work.

†Corresponding author: zhangwei19631126@126.com known to cause bovine mastitis (Fischer-Tenhagen et al., 2018); in particular, Staphylococcus aureus is one of most common pathogens in dairy animals (Schlegelová et al., 2003). Staphylococcus aureus poses a potential public health threat because of the presence of staphylococcal enterotoxins, which can lead to food poisoning, life-threatening endocarditis, septicemia, vomiting, and diarrhea (Shahdordizadeh et al., 2017). Consequently, a rapid and sensitive method for the detection of Staph. aureus in milk is essential for food safety and public health.

Conventional culture-based methods - the gold standard for the detection of Staph. aureus - are inexpensive and reliable; however, these techniques suffer from some shortcomings, including being laborious and time consuming (Dong et al., 2018). Methods based on PCR, such as real-time PCR (Botaro et al., 2013), address these weaknesses because of their specificity and sensitivity but require skilled operation and costly laboratory facilities. Recently, a nucleic acid isothermal amplification method, loop-mediated isothermal amplification (LAMP; Nawattanapaiboon et al., 2015), was developed for the detection of pathogens. However, 4 to 6 primers are required for LAMP, which could lead to the interaction of primers in the reaction system. Furthermore, the primer design of LAMP is intricate and expensive (Suleman et al., 2016; Yang et al., 2016). Rolling circle amplification (RCA; Hao et al., 2017), that is, synthesizing a quantity of DNA fragments from low initial DNA concentrations, has advantages for the detection of pathogens. Nevertheless, to amplify linear DNA, the circularization of padlock probes and ligase are indispensable, making RCA complicated.

Saltatory rolling circle amplification (SRCA) is a new and interesting type of nucleic acid isothermal amplification technique that depends on Bst DNA polymerase, which can synthesize DNA independent of a template (Zyrina et al., 2007). The schematic diagram of the SRCA amplification principle is shown in Figure 1. After a pre-denaturation step, the reverse primer (RVP) combines with the complementary sequence 
in the target single-strand DNA (ssDNA), and the reaction is initiated (step 1). Later, the forward primer (FWP) is bound to the complementary sequence of the newborn DNA strand, producing a double-stranded DNA (step 2). Next, RVP binds to the complementary sequence of the nascent DNA strand and DNA is synthesized at the $3^{\prime}$ end. When the primer binds to the $3^{\prime}$ end of the template, the single DNA strand is displaced and a gapped secondary structure is formed (steps 3,4 ). The FWP binds to complementary region of the secondary structure and extends from the $3^{\prime}$ end to the $5^{\prime}$ end (step 5). When FWP extends to the gap, it can continue to expand by adding several bases with the action of Bst DNA polymerase; Bst continues to add nucleotides when it extends to the $5^{\prime}$ end of the template (step 6). Subsequently, Bst continues to produce new DNA strands and previous DNA strands are replaced and the first-round synthesis amplification has been accomplished (step 7). Then, the extended products of FWP and combined FWP are displaced and a long ssDNA continues to generate. With the extending ssDNA, an increasing number of RVP binding sites are exposed. Then, RVP binds to the corresponding binding sites of new ssDNA (step 8). Each RVP will continue to extend and displace the amplified products. Finally, many tandem repeat units and ssDNA molecules of different lengths are generated (step 9). The FWP binding sites of tandem repeat unit ssDNA are effective for FWP binding and extending (step 10), sequentially producing several linear, double-stranded, tandem repeat unit DNA sequences (containing the target sequence and bases added, step 11).

Different from the LAMP method that was originally published (Notomi et al., 2000), SRCA is simpler, in that it requires only 2 primers, and cheaper, about $50 \%$ of the cost of LAMP. Moreover, the amplification results of SRCA can be ascertained by sequencing. Compared with the RCA method originally published (Lizardi et al., 1998), the need for padlock probes and ligase is averted and the circularization of probes is unnecessary. Under the circumstances of amplification of linear DNA, the operation of SRCA is easy and takes 3 $\mathrm{h}$ less than RCA. The results can be visualized by adding a fluorochrome or observing the white precipitate. In addition, SRCA does not require thermal cycling and just a simple temperature controller is needed, such as a water bath or a heating block.

Considering the aspects described above, the objective of this study was, for the first time, to detect Staph. aureus strains in milk by targeting the factors essential for methicillin-resistance (femA) gene using the SRCA method; femA encodes the factor necessary for methicillin resistance and has high specificity (Li et al., 2008). The SRCA method could efficiently negate the need for expensive instruments and time-consuming electrophoresis, and results could be assessed via visible precipitate or fluorescence. The effectiveness of the developed method was validated by calculating specificity, sensitivity, and detection limits. Finally, we detected Staph. aureus in real milk samples by the SRCA method.

\section{MATERIALS AND METHODS}

\section{Bacterial Strains and Culture Conditions}

In total, 44 different strains were adopted for specificity evaluation (Table 1): 13 Staph. aureus strains and 31 non-Staph. aureus strains. Staphylococcus aureus ATCC 43300 was used for the determination of sensitivity and detection limit. All strains were cultured in nutrient broth (Beijing Land Bridge Technology Co. Ltd., Beijing, China) overnight at $37^{\circ} \mathrm{C}$ for $12 \mathrm{~h}$.

\section{DNA Extraction}

The total DNA of these 44 strains was extracted from fresh overnight-cultured bacteria solution using the EasyPure Bacteria Genomic DNA kit (Takara Biotechnology Co. Ltd., Dalian, China). The DNA samples were stored at $-20^{\circ} \mathrm{C}$ until analyzed and quantified using a NanoDrop 2000 UV-Vis spectrophotometer (Thermo Fisher Scientific, Wilmington, DE) by measuring absorbance (A) at wavelengths of 260 and 280 $\mathrm{nm}$.

\section{Primer Design}

The target gene used for SRCA was femA (GenBank accession No. DQ352467.1). The principle of SRCA primer design is similar to that of the PCR method, and is based on factors such as the GC content, mismatch rate, and so on. The DNAMAN software (Beijing Genomics Institute, Beijing, China) was used to design the primers, which are listed in Table 2.

\section{SRCA and PCR Conditions}

The total volume of the SRCA reaction system was $20 \mu \mathrm{L}$, which contained DNA template $(1.0 \mu \mathrm{L})$, dNTP mixture $(2 \mathrm{~m} M), 10 \times$ ThermoPol Buffer (2 $\mu \mathrm{L}), \mathrm{MgSO}_{4}(3 \mathrm{mM})$, each primer $(0.5 \mu M)$, and Bst DNA polymerase $(8 \mathrm{U})$, with deionized water added to make a final volume of $20 \mu \mathrm{L}$. All of the samples were incubated at $62^{\circ} \mathrm{C}$ for $60 \mathrm{~min}$ and then at $80^{\circ} \mathrm{C}$ for 5 min to end the reaction. The SRCA reaction required a pre-denaturation step $\left(94^{\circ} \mathrm{C}\right.$ for $\left.3 \mathrm{~min}\right)$ and an ice-bath (2 min) before the reaction. 


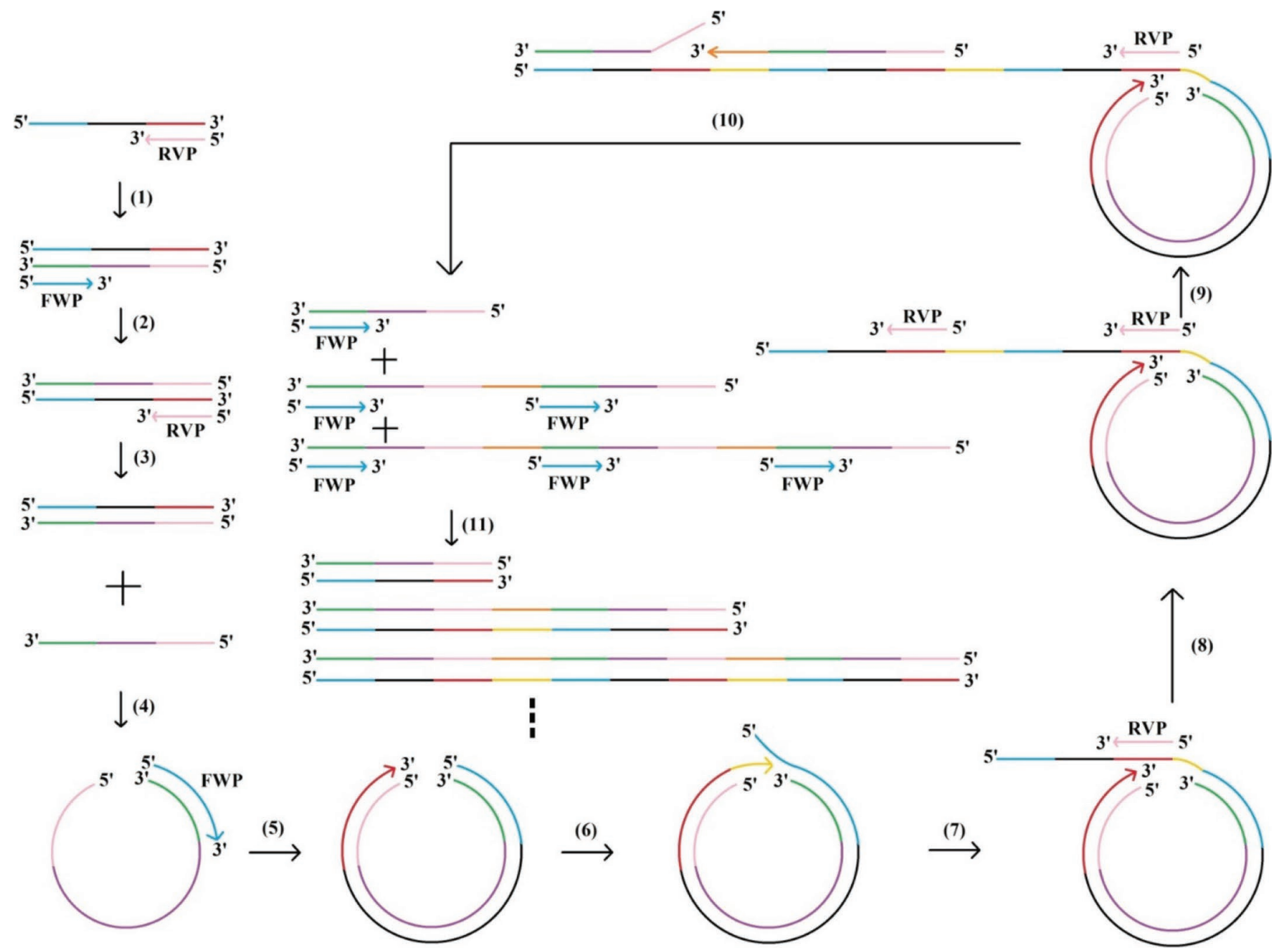

Figure 1. The schematic presentation of the developed saltatory rolling circle amplification (SRCA) method. The blue and pink arrow lines show the forward (FWP) and reverse (RVP) primers, respectively. The black line indicates other sequences in the target template. The green and red lines represent the binding regions of FWP and RVP, respectively. The purple line reflects other sequences of reverse complement of target DNA template. The yellow line indicates the nucleotides added between the $3^{\prime}$ and $5^{\prime}$ ends of the template, and its complementary sequence is highlighted in orange. The ellipsis ( - - ) reveals omitted steps and products. The order of steps (1) to (11) is shown by black arrows. Different lengths of amplification products are shown as double lines of various colors in the last step.

The PCR reaction mixture contained DNA template $(1 \mu \mathrm{L})$, each primer $(0.4 \mu M), 2 \times$ EasyTaq PCR SuperMix (11 $\mu \mathrm{L}$; TransGen Biotech, Beijing, China), and deionized water to $25 \mu \mathrm{L}$. Thermal cycling conditions were as follows: denaturation at $95^{\circ} \mathrm{C}$ for $5 \mathrm{~min}$, followed by 29 cycles $\left(95^{\circ} \mathrm{C}\right.$ for $30 \mathrm{~s}, 58^{\circ} \mathrm{C}$ for $30 \mathrm{~s}$, and $72^{\circ} \mathrm{C}$ for $30 \mathrm{~s}$ ), and a final extension at $72^{\circ} \mathrm{C}$ for $45 \mathrm{~s}$ (Yang et al., 2016).

\section{Restriction Enzyme Digestion and Sequence Analysis of the SRCA Products}

To confirm the specificity of SRCA, the amplicons were digested at $37^{\circ} \mathrm{C}$ for $1 \mathrm{~h}$ using HindIII restriction enzyme (Takara Biotechnology Co. Ltd.) following the instructions. Then, the digested products were analyzed by electrophoresis. Four fragments were cloned for sequencing analysis by Beijing Genomics Institute (Beijing, China).

\section{Sensitivity of the SRCA Assay for Staph. aureus}

To determine the sensitivity of SRCA, 10-fold serial dilutions of Staph. aureus (ATCC 43300) with sterile saline were prepared at DNA concentrations ranging from $7.8 \times 10^{7}$ to $7.8 \times 10^{-1} \mathrm{fg} / \mu \mathrm{L}$. We compared SRCA sensitivity with that of the traditional PCR method. The sensitivity of SRCA was checked by electrophore- 
Table 1. Staphylococcus aureus and non-Staph. aureus strains and their saltatory rolling circle amplification (SRCA) results (positive or negative)

\begin{tabular}{|c|c|c|c|}
\hline No. & Strain & Source $^{1}$ & $\begin{array}{l}\text { SRCA } \\
\text { result }\end{array}$ \\
\hline 1 & Staph. aureus & ATCC 43300 & + \\
\hline 2 & Staph. aureus & ATCC 25923 & + \\
\hline 3 & Staph. aureus & CICC 21600 & + \\
\hline 4 & Staph. aureus & CICC 21648 & + \\
\hline 5 & Staph. aureus & CMCC 26073 & + \\
\hline 6 & Staph. aureus & CMCC 26003 & + \\
\hline 7 & Staph. aureus & LP & + \\
\hline 8 & Staph. aureus & LP & + \\
\hline 9 & Staph. aureus & LP & + \\
\hline 10 & Staph. aureus & LP & + \\
\hline 11 & Staph. aureus & LP & + \\
\hline 12 & Staph. aureus & LP & + \\
\hline 13 & Staph. aureus & LP & + \\
\hline 14 & Staphylococcus epidermidis & CICC 23664 & - \\
\hline 15 & Staphylococcus xylosus & CICC 20237 & - \\
\hline 16 & Staphylococcus xylosus & CICC 22943 & - \\
\hline 17 & Pediococcus acidilactici & CICC 20719 & - \\
\hline 18 & Streptococcus pneumoniae & CICC 10913 & - \\
\hline 19 & Streptococcus pyogenes & CICC 10373 & - \\
\hline 20 & Micrococcus luteus & LP & - \\
\hline 21 & Listeria ivanovii & CICC 21663 & - \\
\hline 22 & Listeria monocytogenes & CICC 21633 & - \\
\hline 23 & Escherichia coli & ATCC 25922 & - \\
\hline 24 & Escherichia coli & CMCC 44103 & - \\
\hline 25 & Escherichia coli & CICC 10372 & - \\
\hline 26 & Escherichia coli $\mathrm{O} 157: \mathrm{H} 7$ & CICC 21530 & - \\
\hline 27 & Diarrheogenic Escherichia coli & CICC 10411 & - \\
\hline 28 & Salmonella enteritidis & CMCC 50041 & - \\
\hline 29 & Salmonella typhimurium & CMCC 50115 & - \\
\hline 30 & Salmonella paratyphi-A & CMCC 50001 & - \\
\hline 31 & Salmonella paratyphi-B & CICC 21495 & - \\
\hline 32 & Shigella flexneri & CMCC 51571 & - \\
\hline 33 & Shigella sonnei & CMCC 51334 & - \\
\hline 34 & Shigella boydii & CMCC 51522 & - \\
\hline 35 & Shigella dysenteriae & CICC 23829 & - \\
\hline 36 & Alicyclobacillus acidoterrestris & ATCC 49025 & - \\
\hline 37 & Vibrio parahaemolyticus & ATCC 17802 & - \\
\hline 38 & Vibrio alginolyticus & CICC 21664 & - \\
\hline 39 & Cronobacter sakazakii & ATCC 29544 & - \\
\hline 40 & Acetobacter pasteurianus & ATCC 33445 & - \\
\hline 41 & Pseudomonas aeruginosa & CICC 21636 & - \\
\hline 42 & Clostridium sordellii & CICC 22950 & - \\
\hline 43 & Proteus bacillus vulgaris & CMCC 49027 & - \\
\hline 44 & Bacillus cereus & CMCC 63302 & - \\
\hline
\end{tabular}

sis and results were visualized by observing the white precipitate or by adding fluorochrome SYBR Green I (1 $\mu \mathrm{L}$ of 1,000×; Takara Biotechnology Co. Ltd.).

\section{SRCA Assays of Milk Spiked with Staph. aureus}

To study the performance of SRCA, milk samples purchased from local supermarkets (Baoding, China) were first tested by a traditional detection method (CFDA, 2016) and a PCR method to confirm the absence of Staph. aureus strains. Staphylococcus aureus
Table 2. Saltatory rolling circle amplification (SRCA) and PCR primers

\begin{tabular}{llc}
\hline Primer & Sequence & $\begin{array}{c}\text { Melting } \\
\text { temperature } \\
\left({ }^{\circ} \mathrm{C}\right)\end{array}$ \\
\hline Forward & 5'AGAGTTTGGTGCATTTACAG-3' $^{\prime}$ & 56.9 \\
Reverse & 5'AGTGGCCAACAGTTTGCGTG-3' $^{\prime}$-AGTTC.0 & 58.0 \\
\hline
\end{tabular}

was then used to artificially contaminate the milk samples. Briefly, $25 \mathrm{~mL}$ of milk sample was homogenized with $225 \mathrm{~mL}$ of sterile $7.5 \%$ sodium chloride broth to produce a homogenate. Then, $1 \mathrm{~mL}$ of the overnightcultured Staph. aureus bacteria solution was serially diluted in $9 \mathrm{~mL}$ of the homogenate. In parallel, $1 \mathrm{~mL}$ of overnight-cultured Staph. aureus was serially diluted in $9 \mathrm{~mL}$ of sterile normal saline for plate counts. The initial concentration of Staph. aureus was $5.6 \times 10^{9}$ $\mathrm{cfu} / \mathrm{mL}$, and concentrations of Staph. aureus in milk homogenate ranged from $5.6 \times 10^{8}$ to $5.6 \times 10^{0} \mathrm{cfu} /$ $\mathrm{mL}$. Subsequently, $1 \mathrm{~mL}$ of each inoculated homogenate was used for DNA extraction. An uninoculated milk sample was used as the negative control. The extracted genomic DNA was used to determine detection limits of SRCA and PCR. The SRCA products were also evaluated by $2 \%$ agarose gel electrophoresis and by production of white precipitate and fluorescence.

\section{Detection of Staph. aureus in Milk Samples}

A total of 90 milk samples were collected from the supermarkets (Baoding, China). The sensitivity, specificity, and accuracy of the SRCA system were determined by comparison with detection of Staph. aureus by ISO methods (ISO, 2016a,b). Statistical significance was defined as $P<0.05$. The equations to calculate sensitivity, specificity, and accuracy are as follows:

$$
\begin{gathered}
\text { Sensitivity: }\left(\mathrm{T}_{\mathrm{pos}}\right) /\left(\mathrm{T}_{\mathrm{pos}}+\mathrm{F}_{\text {neg }}\right) \times 100 \%, \\
\text { Specificity: }\left(\mathrm{T}_{\text {neg }}\right) /\left(\mathrm{T}_{\text {neg }}+\mathrm{F}_{\mathrm{pos}}\right) \times 100 \%, \\
\text { Accuracy: }\left(\mathrm{T}_{\mathrm{pos}}+\mathrm{T}_{\text {neg }}\right) /\left(\mathrm{T}_{\mathrm{pos}}+\mathrm{T}_{\text {neg }}+\mathrm{F}_{\mathrm{pos}}+\mathrm{F}_{\text {neg }}\right) \\
\times 100 \%,
\end{gathered}
$$

where $T_{\text {pos }}$ and $T_{\text {neg }}$ are true positive and true negative samples, confirmed by both ISO and SRCA methods, and $F_{\text {pos }}$ and $F_{\text {neg }}$ are false positive and false negative samples, confirmed only by the ISO or SRCA method, respectively. The experiments were performed over a short period of time in triplicate, each with 3 repeats under the same conditions (method, test samples, laboratory, operator, and equipment) to determine the sensitivity and detection limit. 


\section{RESULTS AND DISCUSSION}

\section{Detection of Staph. aureus by SRCA}

In this study, we adopted the femA gene of Staph. aureus for primer design. The ladder-like bands appeared as a positive reaction by $2 \%$ agarose gel electrophoresis, and were not observed in the negative control (panel A; Supplemental Figure S1; https://doi.org/10.3168/jds .2019-16724). The white precipitate was clearly visible by the naked eye (tube 1), and no white precipitate was found in the negative control (tube 2, Supplemental Figure S1B). As shown in Figure S1C, tube 1 showed a bright green color under daylight, but tube 2 remained
A

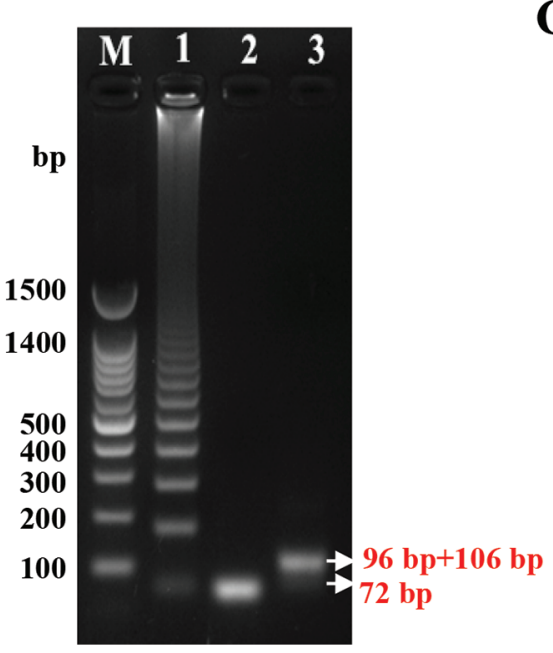

B

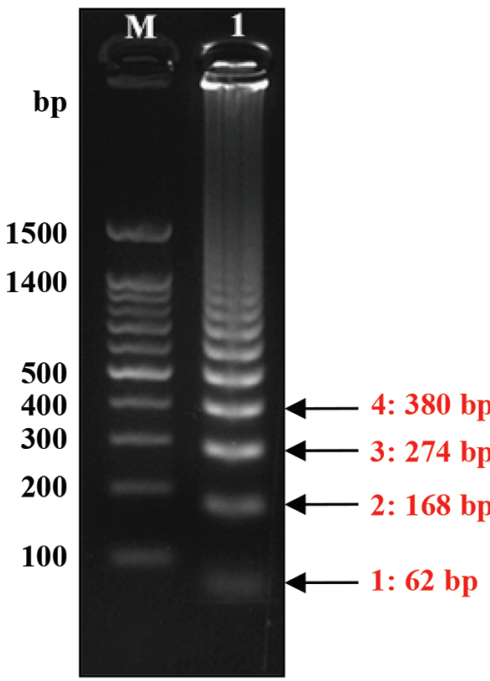

$\mathbf{C}$

1.AGAGTTTGGTGCATTTACAGATAGCATGCCATA CAGTCATTTCACGCAAACTGTTGGCCACT

2.AGAGTTTGGTGCATTTACAGATAGCATGCCATA CAGTCATTTCACGCAAACTGTTGGCCACTATG

AGTTAAAGCTTGCTGAAGGTTATGAAACACAT TTAGTGGAAAGAGTTTGGTGCATTTACAGATA GCATGCCATACAGTCATTTCACGCAAACTGTTG GCCAC

3.AGAGTTTGGTGCATTTACAGATAGCATGCCATA CAGTCATTTCACGCAAACTGTTGGCCACTATG

AGTTAAAGCTTGCTGAAGGTTATGAAACACAT TTAGTGGAAAGAGTTTGGTGCATTTACAGATA GCATGCCATACAGTCATTTCACGCAAACTGTTG GCCAATGAGTTAAAGCTTGCTGAAGGTTATGA AACACATTTAGTGGAAAGAGTTTGGTGCATTT ACAGATAGCATGCCATACAGTCATTTCACGCAA ACTGTTGGCCA

4.AGAGTTTGGTGCATTTACAGATAGCATGCCATA CAGTCATTTCACGCAAACTGTTGGCCACTATG AGTTAAAGCTTGCTGAAGGTTATGAAACACAT TTAGTGGAAAGAGTTTGGTGCATTTACAGATA GCATGCCATACAGTCATTTCACGCAAACTGTTG GCCACATGAGTTAAAGCTTGCTGAAGGTTATG AAACACATTTAGTGGAAAGAGTTTGGTGCATT TACAGATAGCATGCCATACAGTCATTTCACGCA AACTGTTGGCCACTATGAGTTAAAGCTTGCTG AAGGTTATGAAACACATTTAGTGGAAAGAGTT TGGTGCATTTACAGATAGCATGCCATACAGTCA TTTCACGCAAACTGTTGGCCAC

Figure 2. Restriction enzyme and sequence analysis results of saltatory rolling circle amplification (SRCA) products from Staphylococcus aureus. (A) Lane $\mathrm{M}=100$-bp DNA ladder; lane $1=$ SRCA amplification products from Staph. aureus; lane $2=$ PCR amplification products from Staph. aureus; lane $3=$ digestion fragments from SRCA amplification products; (B) lane $\mathrm{M}=100$-bp DNA ladder; lane $1=$ SRCA amplification products from Staph. aureus by $2 \%$ agarose gel electrophoresis; (C) sequencing results of the fragments annotated as 1 to 4 in (B). Sequences highlighted in blue and green correspond to the forward primer (FWP) and the reverse complementary sequence of the reverse primer (RVP), respectively. The sequence beginning from the blue highlight to green highlight indicates the target sequence of $62 \mathrm{bp}$. The sequences in red font are the added nucleotides between the tandem-repeated targeting DNA. 
its original orange color. Compared with the traditional rolling circle amplification method, there is no need for padlock probes and ligase in SRCA, which simplified operation and reduced the time needed. Only 2 primers are required in SRCA, whereas 4 to 6 primers are needed in LAMP, increasing the expenditure and the possibility of interaction among primers. In summary, SRCA is an economical method with the advantage that results can be visualized without specialized equipment.

\section{Validation of the SRCA Products}

To validate the positive SRCA products, amplicons were digested using restriction enzyme HindIII, forming 3 bands at 106, 96, and 72 bp. Only 2 bands are observed in Figure 2A; the upper bands (96 and 106 bp) are close in size and not well separated. Four bands in Figure 2B were sequenced to further validate the SRCA products. The results in Figure 2C showed that the target fragments were $100 \%$ homologous to the femA gene, and the products were composed of tandem-repeated units (containing the target sequence and bases added). These experimental results showed that the SRCA amplification products matched well with the femA target gene in Staph. aureus.

\section{Specificity}

The femA gene exists in all Staph. aureus strains and has been reported to be specific to Staph. aureus (Zhao et al., 2013); it is not found in other Staphylococcus species (Sun et al., 2014). Recently, a PCR assay (McGann et al., 2013) and LAMP method (Xu et al., 2012) targeting femA for the detection of Staph. aureus have been reported, confirming the high specificity of $f e m A$. Therefore, we also adopted $f e m A$ as the specificity assay in this study.

The specificity of the SRCA assay was assessed using 13 Staph. aureus strains and 31 non-Staph. aureus strains (Table 1). As expected, the typical bands on $2 \%$ agarose gel electrophoresis were clearly observed in 13 Staph. aureus and were absent in the 31 non-Staph. aureus strains (Figure 3), suggesting that the SRCA method had high specificity for Staph. aureus.

\section{Sensitivity of SRCA Assay}

The serially diluted DNA extracted from Staph. aureus was used as a template to analyze the sensitivity of the SRCA assay. As concentrations decreased from 7.8 $\times 10^{7}$ to $7.8 \times 10^{1} \mathrm{fg} / \mu \mathrm{L}$, the ladder-like bands increased in size and the white precipitate was obvious. No bands or white precipitate was observed at concentrations of $7.8 \times 10^{0}$ and $7.8 \times 10^{-1} \mathrm{fg} / \mu \mathrm{L}$ (Figure $4 \mathrm{~A}$ and $\mathrm{B}$ )
Therefore, the sensitivity of SRCA was $7.8 \times 10^{1} \mathrm{fg} /$ $\mu \mathrm{L}$ by electrophoresis and by visualization of white precipitate. As shown in Figure 4C, the PCR products were visible at concentrations from $7.8 \times 10^{7}$ to $7.8 \times$ $10^{3} \mathrm{fg} / \mu \mathrm{L}$, but not for concentrations from $7.8 \times 10^{2}$ to $7.8 \times 10^{-1} \mathrm{fg} / \mu \mathrm{L}$. Additionally, by adding fluorochrome SYBR Green I, an obvious green color could be seen as the concentration decreased from $7.8 \times 10^{7}$ to $7.8 \times 10^{0}$ $\mathrm{fg} / \mu \mathrm{L}$, but no color change was observed at $7.8 \times 10^{-1}$ $\mathrm{fg} / \mu \mathrm{L}$ (Figure $4 \mathrm{D}$ ). Therefore, the sensitivity of SRCA was $7.8 \times 10^{0} \mathrm{fg} / \mu \mathrm{L}$ by fluorescence, which was 10 -fold higher than that of electrophoresis or visualization via white precipitate, and 1,000-fold greater than that of the conventional PCR method, respectively.

A

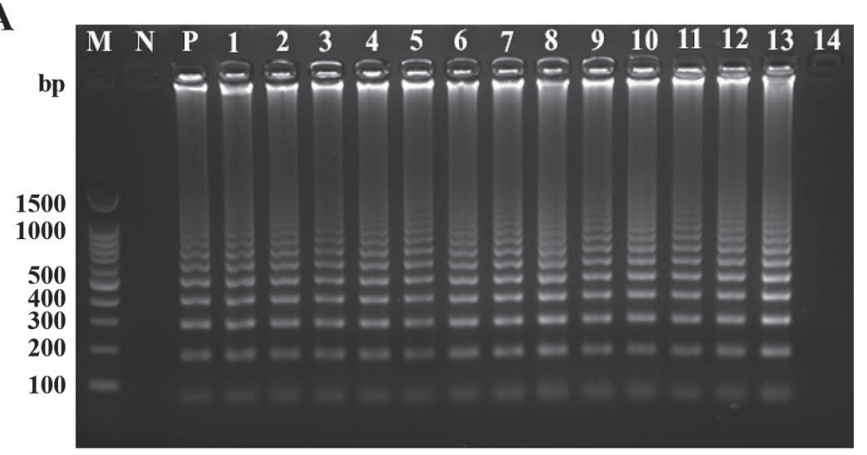

B

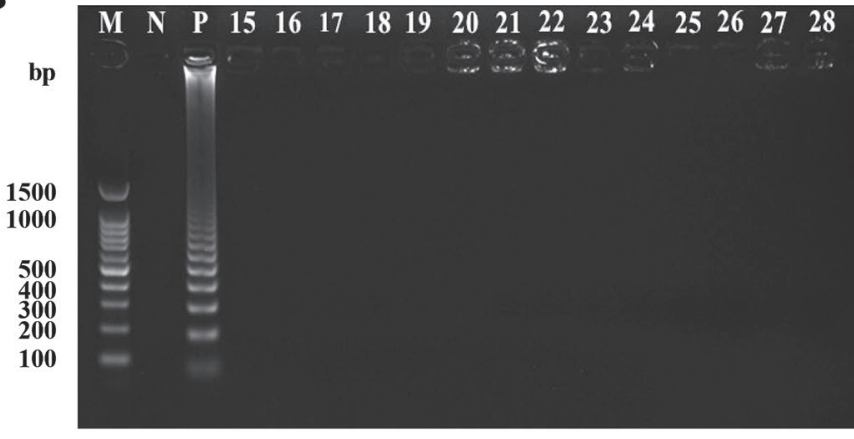

C

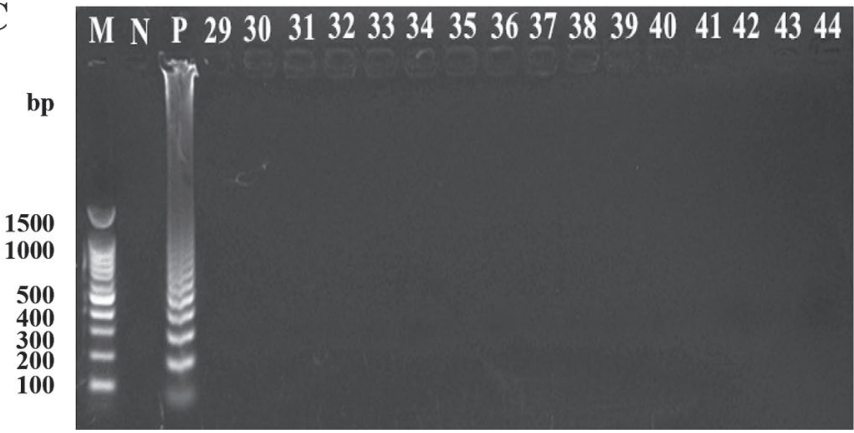

Figure 3. Specificity assay. $\mathrm{M}=100$-bp DNA ladder; $\mathrm{N}=$ negative control; $\mathrm{P}=$ positive control; lanes 1-14 (A) corresponding to strains listed in Table 1; lanes 15-28 (B) as listed in Table 1; lanes 29-44 (C) as listed in Table 1. 
Of particular note, the LAMP assay has been widely applied for the detection of pathogens with high sensitivity. According to a previous report (Sheet et al., 2016), as little as $0.26 \mathrm{pg}$ of Staph. aureus DNA per reaction could be detected by using the LAMP method. A group of LAMP primers was designed for the analysis of Staph. aureus in clinical blood plaque samples and the sensitivity was $1.47 \mathrm{pg} / \mu \mathrm{L}$ (Wang et al., 2015). The sensitivities of our SRCA assay were $7.8 \times 10^{1} \mathrm{fg} /$ $\mu \mathrm{L}$ for detection by electrophoresis and white precipitate; the sensitivity of detection by visualization with fluorescence was $7.8 \times 10^{0} \mathrm{fg} / \mu \mathrm{L}$, which is comparable to that of LAMP-based techniques. Overall, the experimental results showed that the SRCA assay had excellent sensitivity.

\section{Detection of Staph. aureus in Spiked Milk}

We confirmed the detection of Staph. aureus in spiked milk using the SRCA method. The SRCA detection limits of Staph. aureus in spiked milk by electrophoresis and visualization of white precipitate were both $5.6 \times$ $10^{2} \mathrm{cfu} / \mathrm{mL}$ (panels A and B, Supplemental Figure S2; https://doi.org/10.3168/jds.2019-16724). The SRCA

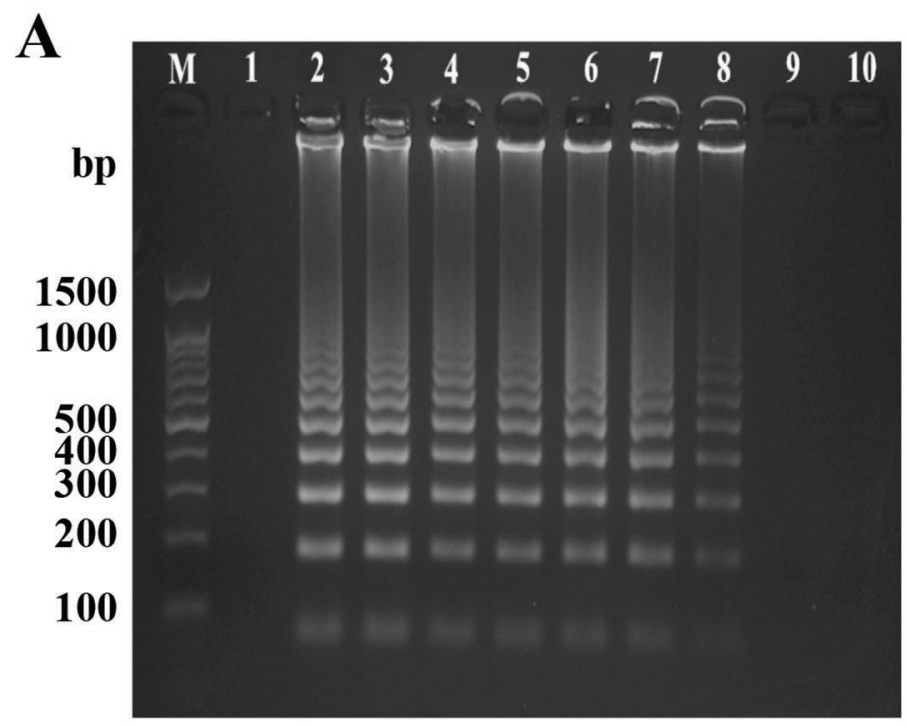

B
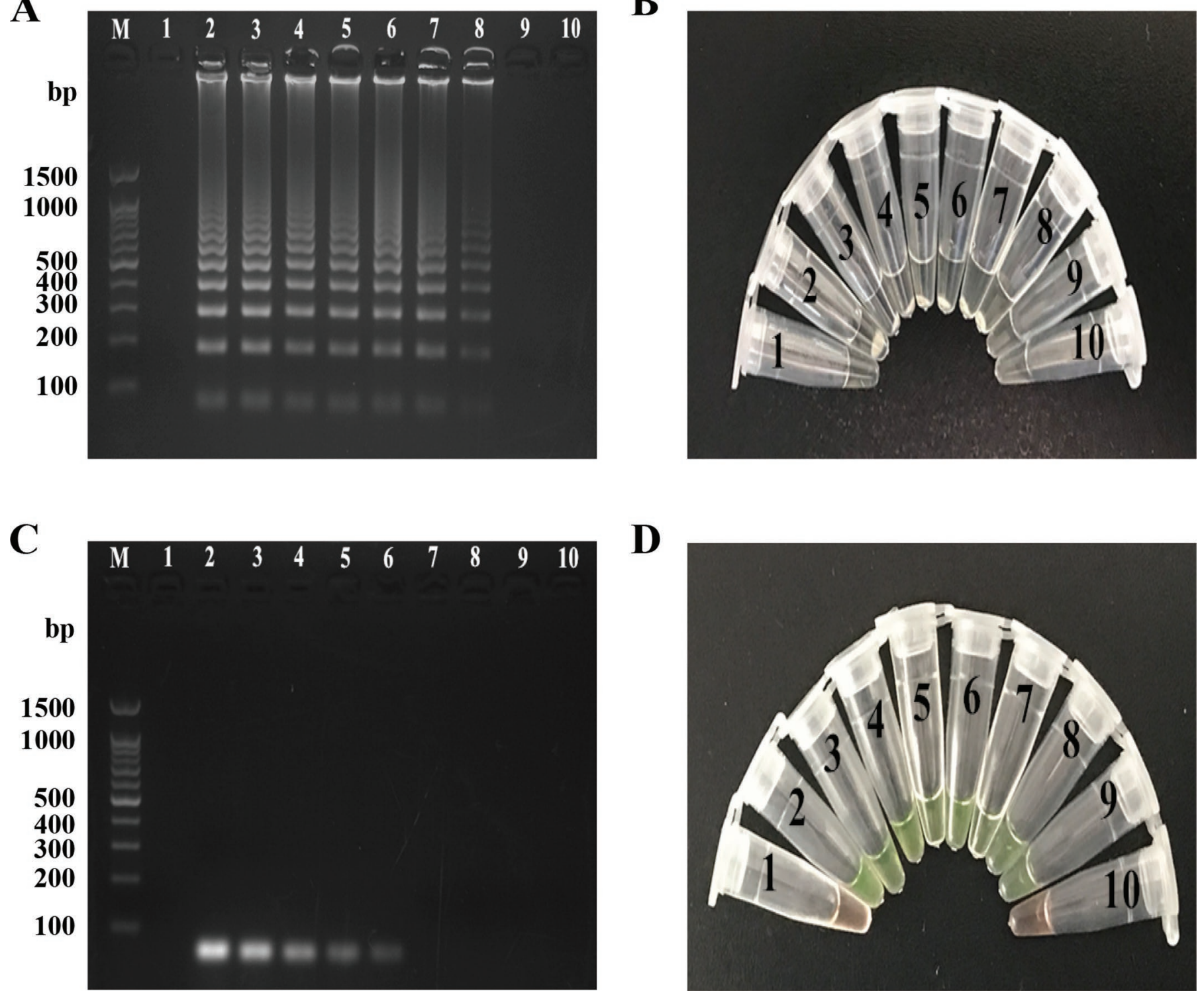

D

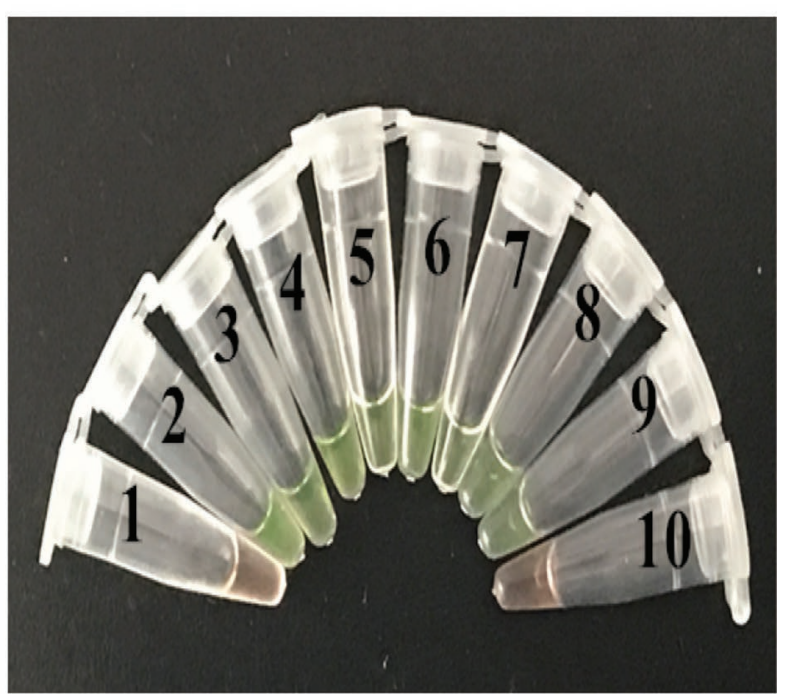

Figure 4. Sensitivities of (A) saltatory rolling circle amplification (SRCA) assay on 2\% agarose gel electrophoresis; (B) SRCA assay determined visually by white precipitate; (C) conventional PCR method by gel electrophoresis; (D) visual SRCA with fluorescence. M = 100-bp DNA ladder; lane $1=$ negative control; lanes $2-10=$ concentrations of template DNA ranging from $7.8 \times 10^{7}$ to $7.8 \times 10^{-1} \mathrm{fg} / \mu \mathrm{L}$. 
method could detect Staph. aureus in spiked milk at $5.6 \times 10^{1} \mathrm{cfu} / \mathrm{mL}$ when fluorochrome SYBR Green I was added (Figure S2C). By comparison, the detection limit of conventional PCR for Staph. aureus was 5.6 $\times 10^{4} \mathrm{cfu} / \mathrm{mL}$ (Figure S2D). The detection limit of a multiplex PCR assay was found to be as low as $10^{3} \mathrm{cfu} /$ $\mathrm{mL}$ (Yu et al., 2015). In brief, the detection limits of SRCA by electrophoresis and white precipitate were 10or 100-fold better than that of the PCR-based assays mentioned above. The detection limits of visualization by fluorescence were 100-fold or 1,000-fold better than those of PCR-based assays.

The minimum infective dose of staphylococcal enterotoxins is $1 \mu \mathrm{g}$, and enterotoxins are produced when Staph. aureus counts in foods exceed $10^{5} \mathrm{cfu} / \mathrm{mL}$ or cfu/g (Ahmed et al., 2019). According to the US Food and Drug Administration regulation, the count of Staph. aureus in raw milk or other dairy products needs to be less than $10^{4} \mathrm{cfu} / \mathrm{mL}$ or $\mathrm{cfu} / \mathrm{g}$, which is similar to that in other countries, such as Australia and New Zealand (Yu et al., 2016). The detection limits of Staph. aureus in artificially contaminated milk by SRCA were $5.6 \times 10^{2} \mathrm{cfu} / \mathrm{mL}$ by electrophoresis and visualization of white precipitate or $5.6 \times 10^{1} \mathrm{cfu} / \mathrm{mL}$ by fluorescence, both of which were lower than $10^{4} \mathrm{cfu} /$ $\mathrm{mL}$, indicating that the SRCA method could be used to detect Staph. aureus in milk and possibly other food products.

\section{Detection of Staph. aureus in Real Milk Samples}

The sensitivity, specificity, and accuracy of the SRAC assay are shown in Supplemental Table S1 (https:// doi.org/10.3168/jds.2019-16724). In this study, 4 milk samples were found to be positive by SRCA, whereas only 2 samples positive for Staph. aureus were detected by the ISO method, perhaps reflecting the fact that the sensitivity of SRCA is much higher than that of the ISO method. In addition, the DNA of viable but nonculturable (VBNC) or dead bacteria can be amplified by the SRCA method. By comparison with the ISO method as reference, the SRCA method had $100.00 \%$ sensitivity, $97.73 \%$ specificity, and $97.78 \%$ accuracy.

\section{CONCLUSIONS}

In this study, we developed a rapid SRCA technique for the detection of Staph. aureus in milk, with sensitivity of $7.8 \times 10^{0} \mathrm{fg} / \mu \mathrm{L}$ in pure culture and a detection limit of $5.6 \times 10^{1} \mathrm{cfu} / \mathrm{mL}$. In particular, SRCA needs only 2 primers to complete the amplification, and a positive result can be visualized by the naked eye as a white precipitate or fluorescence. To the best of our knowledge, this is the first report to use the SRCA method to detect Staph. aureus in milk. The developed method is rapid and sensitive, and is expected to provide a unique opportunity to detect Staph. aureus in various food samples.

\section{ACKNOWLEDGMENTS}

This study was supported by the Key Research and Development Project of Hebei Province (18275501D), the National Natural Science Foundation of China (31371772), the Natural Science Foundation of Hebei Province (C2019204342 and C2017204027), the Scientific Research Program of Hebei Education Department (ZD2017237), and the Program of Introduced Doctor of Hebei Agricultural University (ZD201623), respectively.

\section{REFERENCES}

Ahmed, A. A., N. M. S. Maharik, A. Valero, and S. M. Kamal. 2019 Incidence of enterotoxigenic Staphylococcus aureus in milk and Egyptian artisanal dairy products. Food Control 104:20-27.

Botaro, B. G., C. S. Cortinhas, L. V. Março, J. F. Moreno, L. F. Silva, N. R. Benites, and M. V. Santos. 2013. Detection and enumeration of Staphylococcus aureus from bovine milk samples by real-time polymerase chain reaction. J. Dairy Sci. 96:6955-6964.

CFDA. 2016. GB4789.10-2016. National food safety standard-Food microbiological examination-Examination of Staphylococcus aureus. China Food and Drug Administration, Beijing, China.

Dong, L., H. Liu, L. Meng, M. Xing, J. Wang, C. Wang, H. Chen, and N. Zheng. 2018. Quantitative polymerase chain reaction coupled with sodium dodecyl sulfate and propidium monoazide for detection of viable Staphylococcus aureus in milk. J. Dairy Sci. 101:4936-4943.

Fischer-Tenhagen, C., V. Theby, V. Krömker, and W. Heuwieser. 2018. Detecting Staphylococcus aureus in milk from dairy cows using sniffer dogs. J. Dairy Sci. 101:4317-4324.

Hao, L., H. Gu, N. Duan, S. Wu, X. Ma, Y. Xia, Z. Tao, and Z. Wang. 2017. An enhanced chemiluminescence resonance energy transfer aptasensor based on rolling circle amplification and WS2 nanosheet for Staphylococcus aureus detection. Anal. Chim. Acta 959:83-90.

ISO. 2016a. Microbiology of the food chain-Method validation-Part 2: Protocol for the validation of alternative (proprietary) methods against a reference method (ISO 16140-2:2016). International Organization for Standardization (ISO), Geneva, Switzerland.

ISO. 2016b. Microbiology of the food chain-Method validation-Part 1: Vocabulary (ISO 16140-1:2016). International Organization for Standardization (ISO), Geneva, Switzerland.

Li, X., Y. Xiong, X. Fan, Z. Zhong, P. Feng, H. Tang, and T. Zhou. 2008. A study of the regulating gene of femA from methicillinresistant Staphylococcus aureus clinical isolates. J. Int. Med. Res. $36: 420-433$.

Lizardi, P. M., X. Huang, Z. Zhu, P. Brayward, D. C. Thomas, and D. C. Ward. 1998. Mutation detection and single-molecule counting using isothermal rolling-circle amplification. Nat. Genet. 19:225232.

Nawattanapaiboon, K., W. Kiatpathomchai, P. Santanirand, A. Vongsakulyanon, R. Amarit, A. Somboonkaew, B. Sutapun, and T. Srikhirin. 2015. SPR-DNA array for detection of methicillin-resistant Staphylococcus aureus (MRSA) in combination with loop-mediated isothermal amplification. Biosens. Bioelectron. 74:335-340.

Notomi, T., H. Okayama, H. Masubuchi, T. Yonekawa, K. Watanabe, N. Amino, and T. Hase. 2000. Loop-mediated isothermal amplification of DNA. Nucleic Acids Res. 28:E63.

McGann, P., M. Milillo, Y. I. Kwak, R. Quintero, P. E. Waterman, and E. Lesho. 2013. Rapid and simultaneous detection of the chlorhexi- 
dine and mupirocin resistance genes $q a c A / B$ and mup $A$ in clinical isolates of methicillin-resistant Staphylococcus aureus. Diagn. Microbiol. Infect. Dis. 77:270-272.

Schlegelová, J., M. Dendis, J. Benedík, V. Babák, and D. Rysánek. 2003. Staphylococcus aureus isolates from dairy cows and humans on a farm differ in coagulase genotype. Vet. Microbiol. 92:327-334.

Shahdordizadeh, M., S. M. Taghdisi, N. Ansari, F. A. Langroodi, K. Abnous, and M. Ramezani. 2017. Aptamer based biosensors for detection of Staphylococcus aureus. Sens. Actuators B Chem. 241:619-635.

Sheet, O. H., N. T. Grabowski, G. Klein, and A. Abdulmawjood. 2016. Development and validation of a loop mediated isothermal amplification (LAMP) assay for the detection of Staphylococcus aureus in bovine mastitis milk samples. Mol. Cell. Probes 30:320-325.

Silva, N. C. C., F. F. Guimarães, M. P. Manzi, P. E. Budri, E. GómezSanz, D. Benito, H. Langoni, V. L. M. Rall, and C. Torres. 2013. Molecular characterization and clonal diversity of methicillin-susceptible Staphylococcus aureus in milk of cows with mastitis in Brazil. J. Dairy Sci. 96:6856-6862.

Suleman, E., M. S. Mtshali, and E. Lane. 2016. Investigation of false positives associated with loop-mediated isothermal amplification assays for detection of Toxoplasma gondii in archived tissue samples of captive felids. J. Vet. Diagn. Invest. 28:536-542.

Sun, Z., P. Yuan, M. Zhang, K. Wang, J. Bai, X. Li, B. Ning, and Z. Gao. 2014. Simultaneous and highly sensitive detection of six different foodborne pathogens by high-throughput suspension array technology. Food Control 40:300-309.

Wang, X. R., L. F. Wu, Y. Wang, Y. Y. Ma, F. H. Chen, and H. L. Ou. 2015. Rapid detection of Staphylococcus aureus by loop-mediated isothermal amplification. Appl. Biochem. Biotechnol. 175:882-891.
Xu, Z., L. Li, J. Chu, B. M. Peters, M. L. Harris, B. Li, L. Shi, and M. E. Shirtliff. 2012. Development and application of loop-mediated isothermal amplification assays on rapid detection of various types of staphylococci strains. Food Res. Int. 47:166-173.

Yang, Y., Q. Yang, X. Ma, Y. Zhang, X. Zhang, and W. Zhang. 2016. A novel developed method based on single primer isothermal amplification for rapid detection of Alicyclobacillus acidoterrestris in apple juice. Food Control 75:187-195.

Yu, J., Y. Zhang, H. Li, H. Yang, and H. Wei. 2016. Sensitive and rapid detection of Staphylococcus aureus in milk via cell binding domain of lysin. Biosens. Bioelectron. 77:366-371.

Yu, Q., L. Zhai, X. Bie, Z. Lu, Z. Chong, T. Tao, J. Li, F. Lv, and H. Zhao. 2015. Survey of five food-borne pathogens in commercial cold food dishes and their detection by multiplex PCR. Food Control 59:862-869.

Zhang, Z., W. Liu, H. Xu, Z. P. Aguilar, N. P. Shah, and H. Wei. 2015. Propidium monoazide combined with real-time PCR for selective detection of viable Staphylococcus aureus in milk powder and meat products. J. Dairy Sci. 98:1625-1633.

Zhao, X., Y. Li, M. Park, J. Wang, Y. Zhang, X. He, F. Forghani, L. Wang, G. Yu, and D. H. Oh. 2013. Loop-mediated isothermal amplification assay targeting the femA gene for rapid detection of Staphylococcus aureus from clinical and food samples. J. Microbiol. Biotechnol. 23:246-250.

Zyrina, N. V., L. A. Zheleznaya, E. V. Dvoretsky, V. D. Vasiliev, C. Andrei, and N. I. Matvienko. 2007. N.BspD6I DNA nickase strongly stimulates template-independent synthesis of non-palindromic repetitive DNA by Bst DNA polymerase. Biol. Chem. 388:367-372. 